\title{
Rancang Bangun Aplikasi Modul Pembelajaran Satwa Untuk Anak Berbasis Mobile Augmented Reality
}

\author{
Kholid Fathoni ${ }^{1}$, Yuliana Setiowati ${ }^{2}$, Rozy Muhammad ${ }^{2}$ \\ ${ }^{1}$ Departemen Teknologi Multimedia Kreatif, Teknologi Game, Politeknik Elektronika Negeri Surabaya, Surabaya, Indonesia \\ ${ }^{2}$ Departemen Teknik Informatika dan Komputer, Teknik Informatika, Politeknik Elektronika Negeri Surabaya, Surabaya, \\ Indonesia \\ Email: ${ }^{1}$ kholid@pens.ac.id, ${ }^{2}$ yuliana@pens.ac.id, ${ }^{3}$ rozy_muhammad@ymail.com
}

\begin{abstract}
Abstrak-Pendidikan pada anak merupakan bagian kehidupan yang sangat penting untuk menggapai kesuksesan di masa depan. Sejak dini anak harus diajarkan pengetahuan terutama yang terkait dengan lingkungan sehari-hari, diantaranya: pengenalan satwa. Di antara karakteristik cara belajar anak adalah metodenya menarik. Selama ini pembelajaran konvensional berupa buku membuat anak menjadi bosan sehingga dibutuhkan kreativitas atau metode pembelajaran yang interaktif, salah satunya adalah pembelajaran berbasis multimedia. Salah satu teknologi multimedia yang berkembang saat ini adalah augmented reality. Aplikasi berbasis mobile augmented reality dapat digunakan sebagai media pembelajaran pengenalan satwa bagi anak. Media pembelajaran interaktif pengenalan hewan berbasis Mobile Augmented Reality yang disebut ARnimal ini menggabungkan buku bergambar dan aplikasi augmented reality. Marker yang terdapat pada buku bergambar akan ditangkap oleh kamera dari perangkat mobile kemudian diproses dan tampak animasi 3D hewan pada layar secara realtime. Dengan menggabungkan dunia nyata dan maya, ARnimal dapat merangsang imajinasi anak sehingga anak lebih semangat dalam belajar. Hasil ujicoba ARnimal ini pada beberapa tipe smartphone menunjukkan bahwa semua fungsi ARnimal berjalan dengan baik. ARnimal juga diujicobakan kepada beberapa anak yang didampingi oleh orang tua mereka dan hasil kuesioner menunjukkan bahwa aplikasi ini mudah digunakan, membantu edukasi, memiliki kemiripan dengan satwa nyata serta memiliki tampilan yang menarik.
\end{abstract}

Kata Kunci: Media Pembelajaran, Interaktif, Augmented Reality, 3 Dimensi, Android, Hewan

Abstract-Education in children is a very important part of life to achieve success in the future. Early on, children must be taught knowledge, especially related to the daily environment, including: introduction of animals. Among the characteristics of children's learning is interesting. So far, conventional learning in the form of books makes children bored, so it takes creativity or interactive learning methods, one of which is multimedia-based learning. One of the multimedia technology developed at this time is augmented reality. Mobile augmented reality based applications can be used as learning media for animal recognition for children. This interactive learning media based on Mobile Augmented Reality, called ARnimal, combines picture books and augmented reality applications. The markers contained in the picture book will be captured by the camera from the mobile device and then processed and appear animated 3D animals on the screen in realtime. By combining the real and virtual world, ARnimal can stimulate the imagination of children so that children are more enthusiastic in learning. The results of this ARnimal trial on several types of smartphones show that all ARnimal functions are running well. ARnimal was also tested on some children who were accompanied by their parents and the results of the questionnaire showed that the application was easy to use, helped with education, had similarities with real animals and had an attractive appearance.

Keywords: Learning Media, Interactive, Augmented Reality, 3 Dimensions, Android, Animals

\section{PENDAhUluan}

Pendidikan merupakan kebutuhan yang sangat penting bagi manusia. UNESCO mengemukakan dua prinsip pendidikan yang relevan, pertama pendidik harus di letakkan pada empat pilar yaitu belajar mengetahui (learning to know), belajar melakukan (learning to do), belajar untuk hidup bersama (learning to life together) dan belajar jadi diri sendiri (learning to be), kedua belajar untuk seumur hidup (life long learning)[1]. Pendidikan Nasional bertujuan untuk mengembangkan kemampuan dan membentuk watak atau karakter dengan budi pekerti luhur yang diharapkan mampu membangun peradaban bangsa yang bermartabat[2].

Belajar merupakan suatu proses di mana manusia mengubah perilakunya yang disebabkan adanya pengalaman[3]. Hal ini dapat dihubungkan dengan pernyataan ahli filosofis Yunani, Plato, yang terkait dengan pendidikan. Plato mengatakan bahwa pendidikan menyebabkan orang lebih baik dan orang baik akan memiliki perilaku mulia [4]. Belajar adalah hasil dari pengalaman, didalamnya terjadi beberapa stimulus dan respon; manusia belajar dari lingkungan (diluar dirinya) yang terinternalisasi melalui stimulus yang menyebabkan responsrespons emosional [3]. Proses pembelajaran dimulai dari anak-anak. Anak-anak memiliki karakteristik yang berbeda dengan orang dewasa dalam berperilaku. Dengan demikian dalam hal belajar anak juga memiliki karakteristik yang tidak sama pula dengan orang dewasa. Karakteristik cara belajar anak merupakan fenomena yang harus dipahami dan dijadikan acuan dalam merencanakan dan melaksanakan pembelajaran untuk anak usia dini. Karakterisktik cara belajar anak [5] sebagai berikut:

1. anak belajar melalui bermain,

2. anak belajar dengan cara membangun pengetahuanya,

3. anak belajar secara alamiah,

4. anak belajar paling baik jika apa yang di pelajari mempertimbangkan keseluruhan aspek pengembangan, bermakna, menarik, dan fungsional. 
Butir ke-4 menunjukkan bahwa pembelajaran bagi anak harus menarik. Pembelajaran akan lebih efektif dan menarik apabila menggunakan metode yang interaktif atau berbasis interaksi. Kreativitas mengelola proses pembelajaran diperlukan agar mampu menyajikan pembelajaran yang menyenangkan [5]. Dalam strategi pembelajaran, ketika guru mengajar belum tentu siswanya belajar; ketika siswa banyak melakukan aktivitas, itulah sebenarnya saat siswa belajar[6].

Saat ini banyak metode atau teknologi yang digunakan untuk menarik minat anak-anak untuk aktif dalam proses pendidikan. mulai dari penggunaan buku bergambar maupun video interaktif. Namun metode-metode tersebut saat ini dinilai sudah terlalu umum dan teknologi tersebut bukan merupakan teknologi yang paling baru. Karena perkembangan teknologi multimedia semakin berkembang, ragam metode dan media pembelajaran juga semakin banyak. Salah satu contohnya ada lah media pembelajaran dengan menggunakan teknologi terbaru yaitu Augmented Reality. Penggunaan teknologi multimedia yang terbaru sebagai contoh AR (Augmented Reality) dinilai lebih interaktif dan dapat merangsang daya imajinasi anak sehingga dapat lebih menarik minat anak untuk belajar.

Dalam bidang pendidikan, teknologi AR dapat digunakan sebagai pelengkap media pembelajaran yang sudah ada saat ini, dengan teknologi AR ini diharapkan dapat menarik minat pembaca, dikarenakan dengan media pembelajaran berbasis AR ini pembaca dapat secara aktif berinteraksi dengan aplikasi. Teknologi AR ini prinsipnya secara umum masih sama dengan virtual reality, yaitu bersifat interaktif, immersion (membenamkan/memasukkan), real-time, dan obyek maya biasanya berbentuk tiga dimensi. Namun kebalikan dari virtual reality yang menggabungkan obyek nyata kedalam lingkungan maya, AR menggabungkan obyek maya pada lingkungan nyata.

Berdasarkan latar belakang tersebut, pengenalan terhadap lingkungan sekitar khususnya hewan pada anak sangatlah penting sehingga dalam penelitian ini diharapkan dapat memberikan terobosan yang menarik dalam membantu anak-anak mengenal hewan sejak dini dengan memberikan sebuah aplikasi modul pembelajaran interaktif tentang pengenalan hewan berbasis Mobile Augmented Reality.

\section{METODE PENELITIAN}

\subsection{Kerangka Penelitian}

Dalam perancangan dan pembuatan media pembelajaran ARnimal ini terdapat beberapa tahapan-tahapan proses yaitu: studi pendahuluan, perancangan dan pembuatan, serta pengujian. Studi pendahuluan meliputi beberapa subproses yaitu: studi lapangan, strudi literatur dan analisa kebutuhan. Perancangan dan pembuatan meliputi: penyusunan naskah ARbook, pembuatan model 3D, modelling, texturing, pembuatan pola marker, penguji pola marker, serta perancangan Layout ARbook. Tahap pengujian terdiri atas: ujicoba terbatas, sampai dengan menjadi aplikasi final. Secara detil proses ini ditunjukkan gambar berikut.

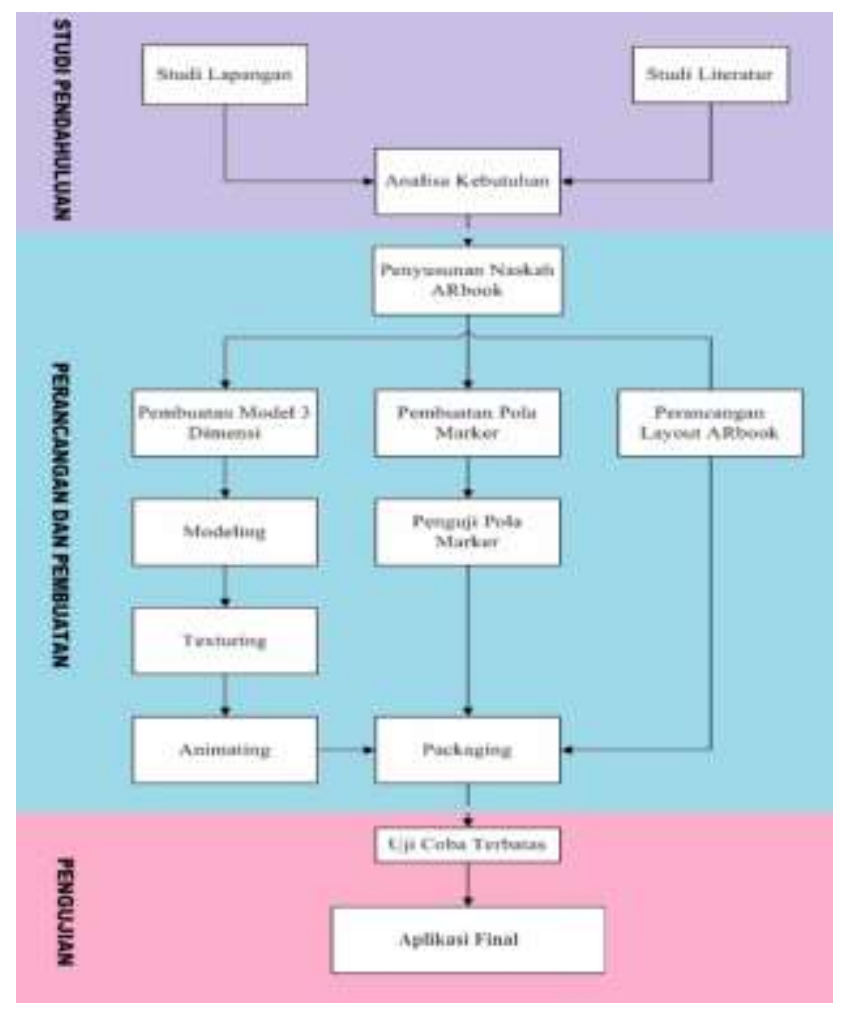

Gambar 2. Proses Pengembangan ARnimal 
Sebagai tahap awal suatu penelitian, studi lapangan sangatlah penting untuk mengumpulkan berbagai informasi dasar yang akan berguna dalam membantu proses penelitian selanjutnya. Dari studi lapangan dapat diketahui gambaran mengenai keadaan, masalah atau potensi yang dapat dimanfaatkan sebagai acuan pengembangan produk penelitian. Secara spesifik studi eksploratif difokuskan kepada pengumpulan informasi mengenai materi yang akan diimplementasikan ke dalam produk penelitian.

Studi literatur dilakukan tidak hanya untuk mengumpulkan dan mengetahui teori-teori pendukung penelitian, tetapi juga berbagai informasi yang berkaitan dengan produk yang akan dibuat, yaitu media berbasis augmented reality. Karena penelitian ini lebih difokuskan pada pengembangan produk, maka diperlukan berbagai informasi mengenai kebutuhan pengembangan produk, langkah-langkah atau prosedur pengembangan produk yang tepat, dan sebagainya. Hal ini dapat diperoleh dari buku, jurnal, paper, artikel atau penelitian sejenis yang telah dilakukan sebelumnya.

\subsection{Penelitian Terkait}

Terdapat beberapa penelitian sebelumnya yang terkait dengan penelitian sebagai berikut:

1. "Perancangan Dan Implementasi Interaksi Untuk Media Pembelajaran Manasik Berbasis Augmented Reality" oleh Husnul Rizka Mubarikah, Teknik Elektro, Institut Teknologi Bandung (ITB) pada tahun 2009. Pada penelitian ini dibuat media pembelajaran manasik haji. Dalam penelitian ini, sang penulis membuat suatu media pembelajaran untuk para calon jemaah haji untuk membantu memberikan pengenalan dan pemahaman segala aktivitas-aktivitas ibadah haji dan umroh. Media pembelajaran Ibadah Haji yang diberi nama BuMI tersebut adalah sebuah media pembelajaran yang menggabungkan dunia nyata yaitu buku bergambar dan dunia fiktif dengan menggunakan teknologi Augmented Reality yang merupakan aplikasi desktop. Proses pembuatannya menggunakan software ARToolkit. Dalam media ini terdapat berbagai macam metode yaitu video, simulasi, puzzle, dan kuis. Dalam masing-masing metode tersebut menggunakan marker yang berguna sebagai penanda dan juga sebagai pelengkap media tersebut. Dengan media pembelajaran ini para calon jamaah haji dan umroh dapat lebih paham dan mengerti tentang segala aktivitas haji karena para pengguna seakan-akan dapat merasakan suasana haji[8].

2. "Media Pembelajaran Sistem Tata Surya Berbasis Augmented Reality" oleh Anggar Sasmito pada tahun 2011. Media pembelajaran ini menggunakkan ARToolkit seperti Media Pembelajara BuMI karya Husnul Rizka. Namun jika BuMI adalah panduan Ibadah haji dan umroh, media pembelajaran ini dapat mengenalkan sistem tata surya. Mulai dari anggota tata surya maupun pergerakan dan sistem tata surya kita. Media pembelajaran ini juga merupakan aplikasi desktop yang memerlukan marker. Dengan menggunakan ilustrasi dan simulasi yang mirip dengan sistem tata surya yang sebenarnya menyebabkan para pengguna dapat mengetahui dan mengerti tentang sistem tata surya[9].

\subsection{Unity Game Engine}

Unity adalah jenis mesin game yang dikembangkan oleh perusahaan pengembang video game bernama Unity Technologies. Mesin Unity memungkinkan pengembang membuat game 2D dan 3D. Saat ini hanya mendukung bahasa pemrograman C \#. Unity mendukung Direct3D, OpenGL, OpenGL ES, Metal, Vulkan, dan API eksklusif. Sejak 2016, Unity menawarkan layanan di cloud. [10]. Unity didukung pada Windows dan macOS, serta 27 platform lainnya. [11] Pada 2016 Unity berubah dari pembelian satu kali menjadi model berlangganan. Saat ini terdapat satu opsi lisensi gratis dan tiga berbayar: Pribadi (Gratis), Plus, Pro, Enterprise[12]. Unity memiliki koleksi kuat tutorial resmi untuk membantu membiasakan pengembang baru dengan mesin. Selain itu, ia memiliki dokumentasi menyeluruh yang diperbarui agar akurat dengan setiap rilis Persatuan baru. Tutorial dan dokumentasi memanfaatkan aset pra-dibangun yang tersedia di program Unity default. Pengembang dapat menggunakan ini alih-alih dipaksa untuk menulis semua kode mereka dari awal[13] [14].

\subsection{Augmented Reality}

Menurut Ronald T. Azuma[10], augmented reality merupakan penggabungan obyek nyata dan maya di lingkungan nyata yang berjalan secara interaktif dalam waktu nyata, dimana benda maya terintegrasi dalam dunia nyata. Penggabungan benda nyata dan maya dimungkinkan dengan teknologi tampilan yang sesuai, interaktivitas dimungkinkan melalui perangkat-perangkat masukan tertentu, serta integrasi yang baik memerlukan penjejakan yang efektif. Milgram dan Kishino dalam Billinghurst menjelaskan konsep augmented reality sebagai bagian dari virtuality continuum yang dapat dilihat dalam gambar berikut ini:

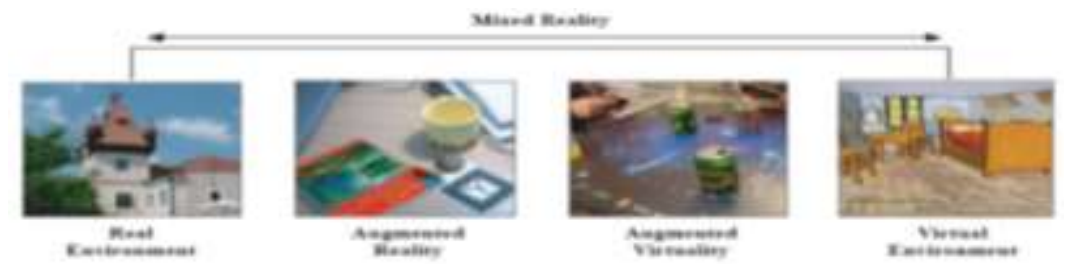

Gambar 1. Virtuality Continuum 
Milgram dan Kishino merumuskan kerangka kemungkinan penggabungan dan peleburan dunia nyata dan dunia maya ke dalam sebuah Virtuality Continuum[11]. Sisi yang paling kiri adalah lingkungan nyata yang hanya berisi benda nyata, dan sisi paling kanan adalah lingkungan maya yang berisi benda maya. Dalam augmented reality atau realitas tertambah, yang lebih dekat ke sisi kiri, lingkungan bersifat nyata dan benda bersifat maya, sementara dalam augmented virtuality atau virtualitas tertambah, yang lebih dekat ke sisi kanan, lingkungan bersifat maya dan benda bersifat nyata. Realitas tertambah dan virtualitas tertambah digabungkan menjadi mixed reality atau realitas campuran.

\subsection{Vuforia}

Vuforia adalah perangkat pengembangan perangkat lunak augmented reality (SDK) untuk perangkat seluler yang mendukung pembuatan aplikasi berbasis augmented reality[12]. Vuforia menggunakan teknologi visi komputer untuk mengenali dan melacak gambar planar dan objek 3D secara real time. Kemampuan registrasi gambar ini memungkinkan pengembang untuk memposisikan dan mengarahkan objek maya, seperti model 3D dan media lainnya, dalam kaitannya dengan objek dunia nyata melalui kamera perangkat seluler. Objek maya kemudian melacak posisi dan orientasi gambar secara real-time sehingga perspektif pengguna pada objek sesuai dengan perspektif pada target.

Vuforia SDK mendukung berbagai jenis obyek 2D dan 3D. Fitur tambahan SDK termasuk Deteksi Oklusi terlokalisasi menggunakan 'Tombol Virtual', pemilihan target gambar runtime, dan kemampuan untuk membuat dan mengkonfigurasi ulang set target secara terprogram saat runtime [13].

\section{HASIL DAN PEMBAHASAN}

\subsection{Rancangan Kerja Sistem}

Sistem yang dibangun dalam penelitian ini adalah sebuah aplikasi media pembelajaran interaktif pengenalan hewan dengan memanfaatkan teknologi Mobile Augmented Reality. Media Pembelajaran ini terdiri atas dua hal yaitu Buku Marker (ARbook) dan sebuah aplikasi pada Android. ARbook berisi informasi tentang pengenalan hewan dan marker. Marker ini yang nantinya diterjemahkan oleh aplikasi Android dan pada layar smartphone akan muncul objek 3D dari hewan. Adapun gambaran dari sistem ini adalah sebagai berikut :

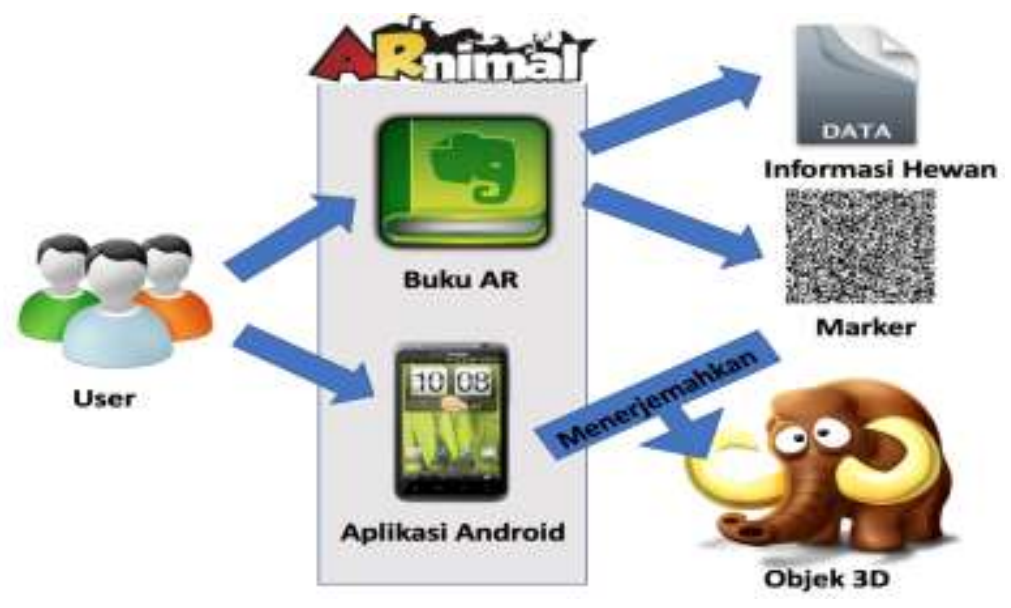

Gambar 3. Diagram Sistem

ARnimal terdiri atas Buku Penunjang (ARbook) dan Aplikasi pada Smartphone Android. Pengguna dapat membaca informasi hewan pada buku dan juga melihat objek 3 Dimensi hewan yang berasal dari aplikasi Android yang menerjemahkan Marker yang terdapat pada Buku.

\subsection{Use Case Diagram}

Use case merupakan gambaran interaksi antara user dengan sistem. Sebuah diagram use case menggambarkan hubungan antara actor dengan kegiatan yang dapat dilakukan terhadap aplikasi. Media pembelajaran ini merupakan gabungan antara buku bergambar (ARbook) dan aplikasi pada smartphone Android. Pada media pembelajaran ini, user dapat melakukan lima hal yaitu user dapat membaca informasi pengenalan hewan dan membaca cara pemakaian media pembelajaran pada ARbook, kemudian User dapat menggunakan software pada smartphone untukmembuka aplikasi, melihat objek 3Dimensi hewan dan keluar dari aplikasi tersebut.

Dibawah ini merupakan gambaran use case dari media pembelajaran Augmented Reality yang dibangun pada penelitian ini: 


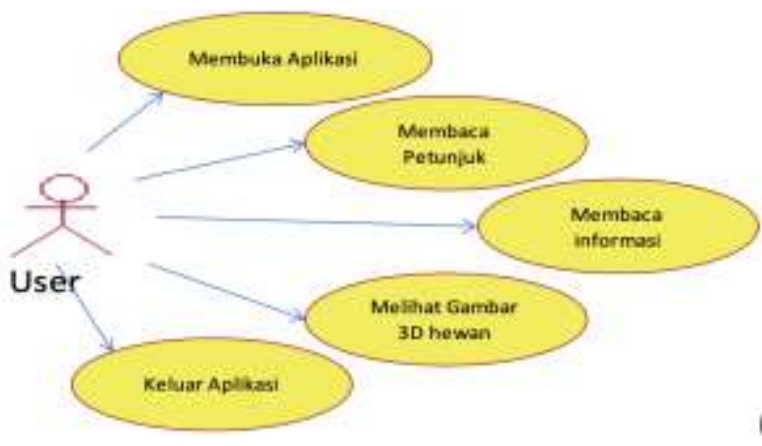

Gambar 4. Diagram Use Case

\subsection{Diagram Augmented Reality}

Struktur media terbagi menjadi dua bagian, yaitu bentuk fisik (media cetak berupa buku), dan aplikasi Augmented Reality. Beberapa komponen yang harus dibuat yaitu marker, pattern, dan objek 3 dimensi. Prosesnya sebagai berikut: marker dalam ARbook dibaca oleh kamera; gambar dari kamera smartphone yang masuk akan dibaca oleh aplikasi dan diidentifikasi sebagai pattern marker objek tertentu; aplikasi akan memanggil objek 3 dimensi sesuai dengan pattern marker yang terbaca; objek 3 dimensi tersebut kemudian ditampilkan diatas marker melalui output pada layar smartphone selanjutnya proses akan diulang terhadap marker-marker berikutnya; sehingga satu marker berkorespondensi dengan satu pattern dan satu pattern berkorespondensi dengan satu objek 3 dimensi.

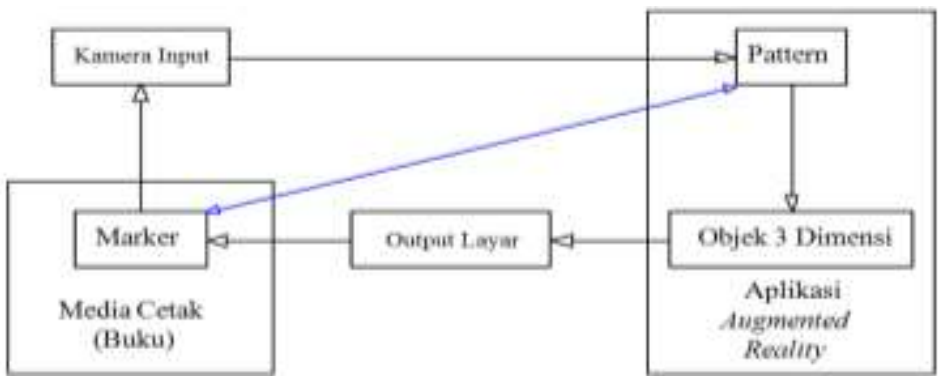

Gambar 5. Diagram Augmented Reality

\subsection{Implementasi Sistem}

Desain implementasi sistem dari aplikasi ARnimal berawal dari proses modelling 3D hewan menggunakan SketchUp dan animasi menggunakan 3Dblender. Setelah itu proses selanjutnya adalah membuat design tampilan untuk gameplay dengan mernggunakan game engine Unity. photoshop dan corelDraw untuk pembuatan menu, icon dan tampilan 2D lainnya. Setelah itu memasuki proses integrasi untuk Augmented Reality dengan menggunakan Vuforia SDK dari Qualcomm. Untuk proses Scripting menggunakan bahasa microsoft Visual C\#. Setelah semua fase tersebut selesai, maka langkah terakhir yaitu mengeksportnya ke dalam format .apk agar nantinya bisa di instal pada smartphone Android. Secara detil prosesnya ditunjukkan gambar berikut ini.

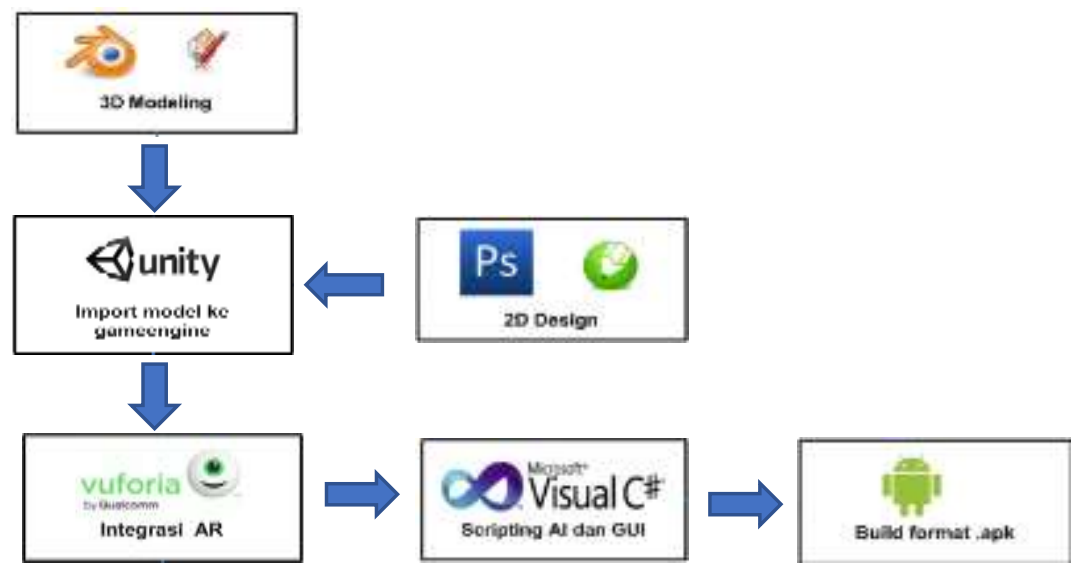

Gambar 6. Diagram Implementasi Sistem 
JURNAL MEDIA INFORMATIKA BUDIDARMA

Volume 4, Nomor 1, Januari 2020, Page 32-41

ISSN 2614-5278 (media cetak), ISSN 2548-8368 (media online)

Available Online at https://ejurnal.stmik-budidarma.ac.id/index.php/mib DOI $10.30865 /$ mib.v4i1.1797

\section{a. Pemilihan Jenis Hewan}

Hewan - hewan yang ditampilkan pada Media Pembelajaran ARnimal ini merupakan hewan yang hidup di darat dan hidup di air yang berada di wilayah Indonesia. Hewan-hewan yang ditampilkan pada media pembelajaran ini adalah sebagai berikut: anjing, babi, badak, banteng, beruang, buaya, domba, gajah, gorila, hiu, harimau, jerapah, kelinci, komodo, kucing, kuda, kudanil, lumba-lumba, panda, paus, rusa, singa, sapi, unta, zebra. Pada Media Pembelajaran ARnimal ini akan diberikan informasi permodelan 3 Dimensi untuk masing-masing hewan tersebut.

\section{b. Pemilihan Marker}

Marker merupakan hal yang penting dalam proses Augmented Reality, dimana marker tersebut adalah penanda dan juga pemicu objek 3 Dimensi yang akan ditampilkan. Marker yang dipakai pada penelitian ini terlebih dahulu di upload pada web vuforia SDK kemudian dinilai apakah marker tersebut merupakan marker yang baik dan nantinya menjadi pemicu / trigger yang baik dalam proses Augmented Reality.

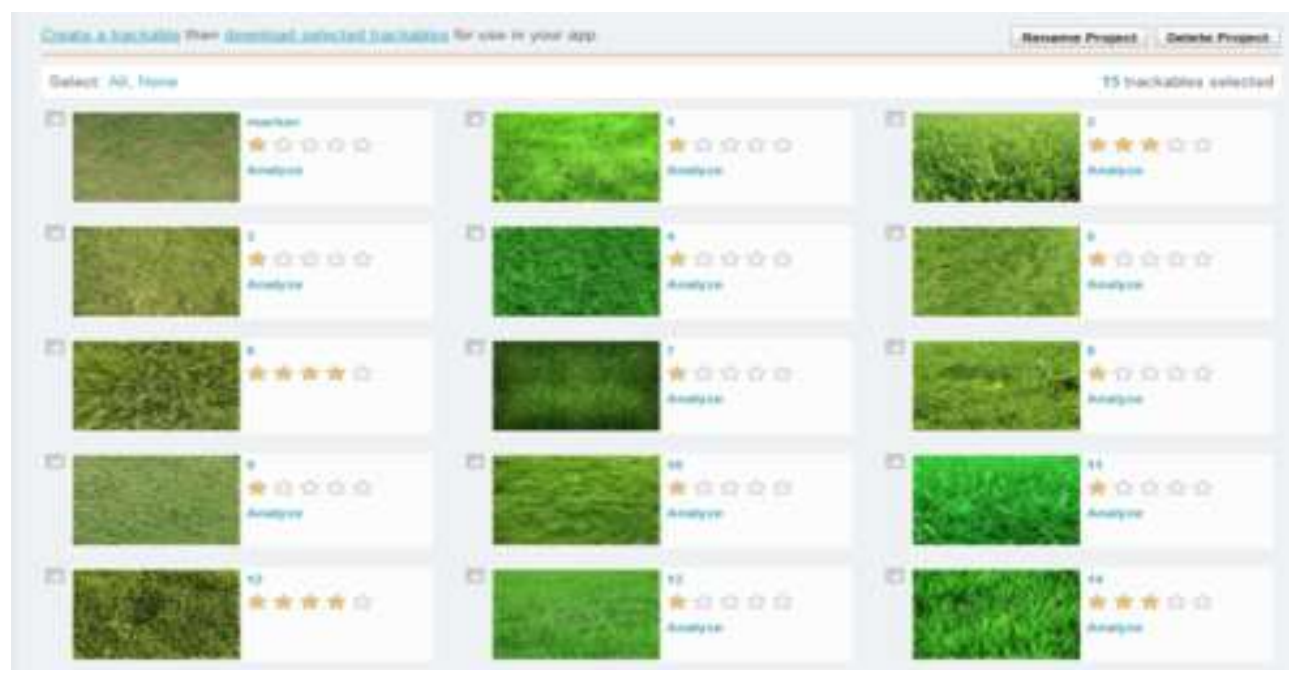

Gambar 7. Beberapa Marker yang Disiapkan

\section{c. Perancangan ARbook}

Tahap perancangan buku AR menggunakan photoshop dan CorelDraw. Buku ini dikonsep dengan ukuran A5 format landscape. Untuk sisi kiri dari buku adalah tempat meletakkan ensiklopedi hewan sedangkan sisi kanan sebagai marker. Konsep desain layout buku tersebut mengambil tema "cut-out stationary" dimana desainnya menggambarkan hasil karya anak-anak seperti menggunting gambar dan lain-lain. Gambar berikut adalah salah satu contoh design halaman buku AR.

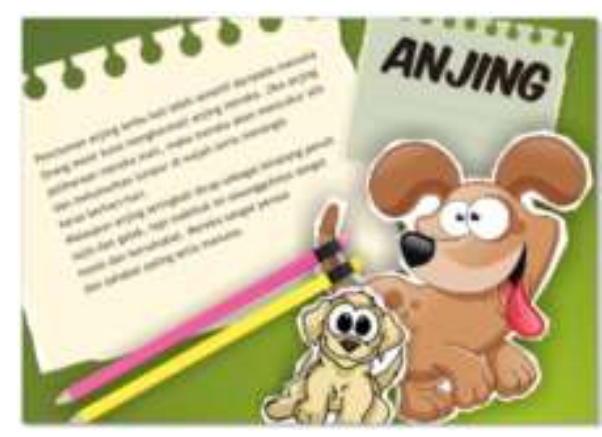

Gambar 8. Desain ARbook

\section{d. Desain Model 3D}

Pada tahap ini dilakukan permodelan dan pembentukan karakter hewan 3D. Permodelan tersebut meliputi bentuk, tekstur dan material kulit/skin. Setelah model hewan 3D telah selesai dibentuk kemudian dilanjutkan dengan proses desain animasi 3D hewan. Desain animasi 3D hewan harus menyerupai perilaku hewan sebenarnya. Proses desain animasi ini diawali dengan memberikan armature/tulang kepada objek 3D hewan. Tulang ini yang nantinya sebagai dasar untuk membuat gerakan-gerakan animasi 3D yang fungsinya sama seperti tulang pada manusia atau hewan. Setelah memberikan tulang dilakukan animasi 3D dengan cara menggerakkan tulang-tulang tersebut. Setelah hal itu selesai dilakukan kemudian dieksport ke dalam format .fbx untuk proses selanjutnya. 
Available Online at https://ejurnal.stmik-budidarma.ac.id/index.php/mib DOI 10.30865/mib.v4i1.1797

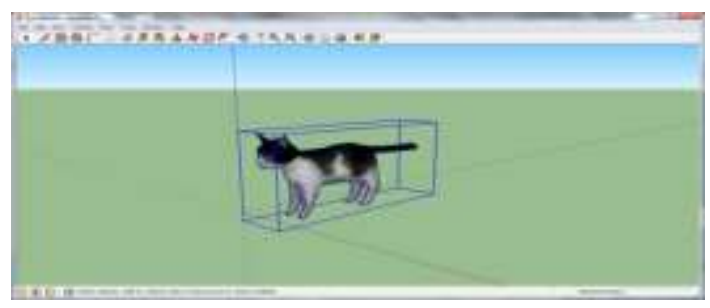

Gambar 9 Design Model 3D

\section{e. Perancangan Interface}

Desain Interface diarahkan agar aplikasi terlihat menarik dan mudah digunakan serta agar user dapat menangkap isi dari informasi yang disampaikan. Desain interface menu awal ditunjukkan gambar berikut.

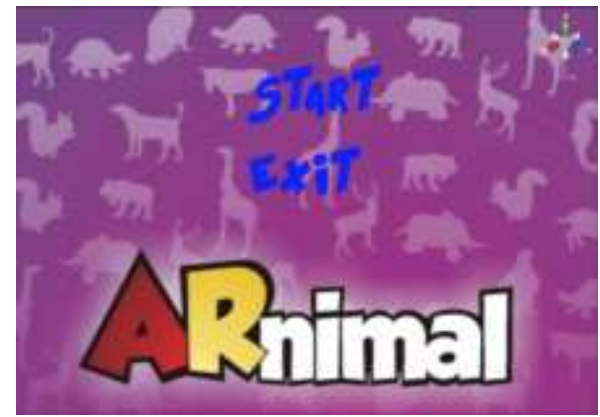

Gambar 10. Desain Interface

\subsection{Impelementasi}

Pengujian sistem dari aplikasi pembelajaran hewan untuk anak berbasis augmented reality Arnimal dilakukan dengan 2 cara yaitu ujicoba 3D Rendering dan ujicoba performa.

\subsubsection{Ujicoba 3D Rendering}

Ujicoba rendering dilakukan terhadap 25 model hewan 3D yaitu: anjing, babi, badak, banteng, beruang, buaya, domba, gajah, gorila, hiu, harimau, jerapah, kelinci, komodo, kucing, kuda, kudanil, lumba-lumba, panda, paus, rusa, singa, sapi, unta, zebra. Hasil ujicoba ditunjukkan pada tabel berikut.

Tabel 1. Hasil Ujicoba 3D Rendering Terhadap 25 Model Hewan 3D

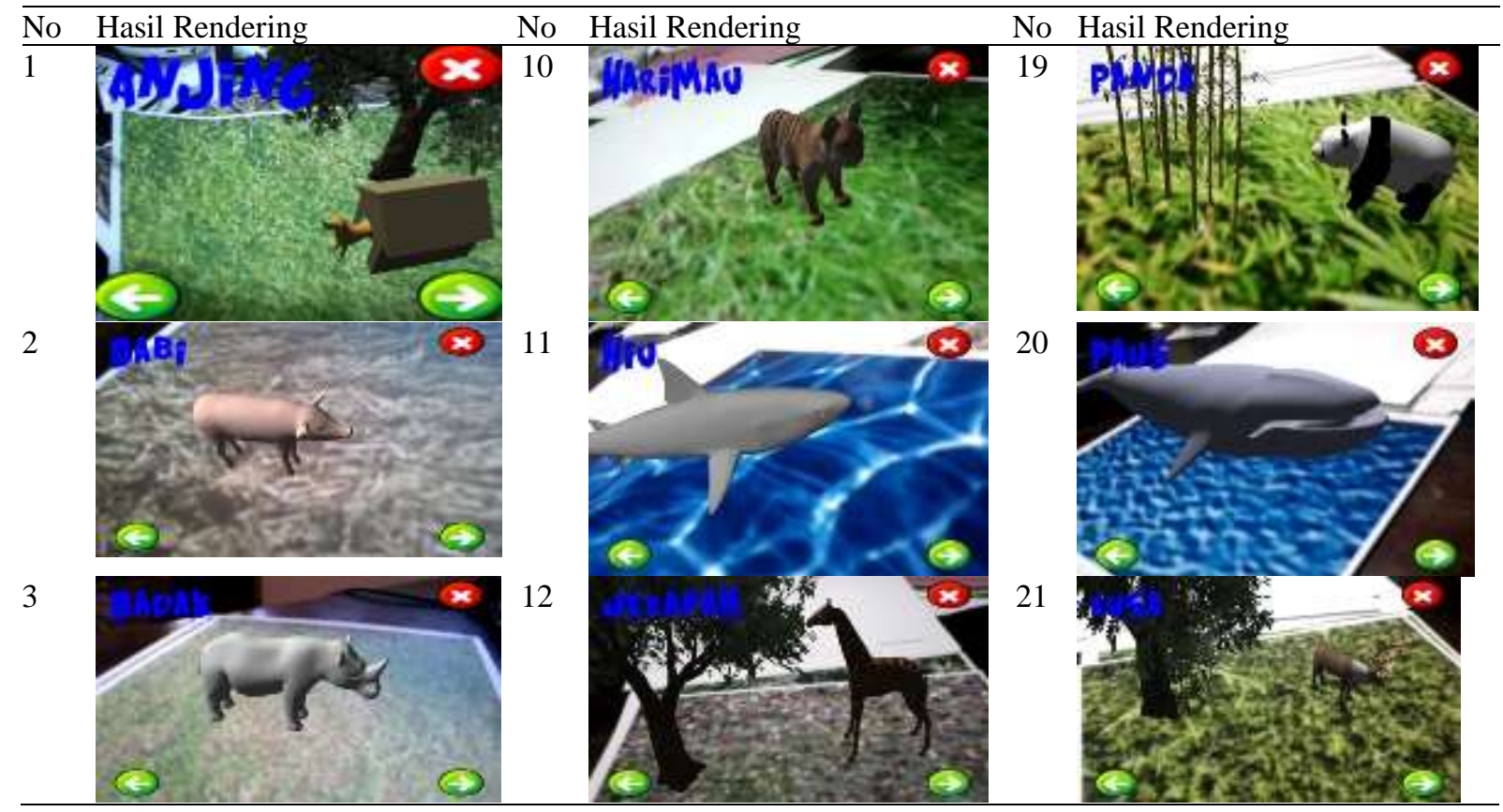


JURNAL MEDIA INFORMATIKA BUDIDARMA

Volume 4, Nomor 1, Januari 2020, Page 32-41

ISSN 2614-5278 (media cetak), ISSN 2548-8368 (media online)

Available Online at https://ejurnal.stmik-budidarma.ac.id/index.php/mib DOI $10.30865 /$ mib.v4i1.1797

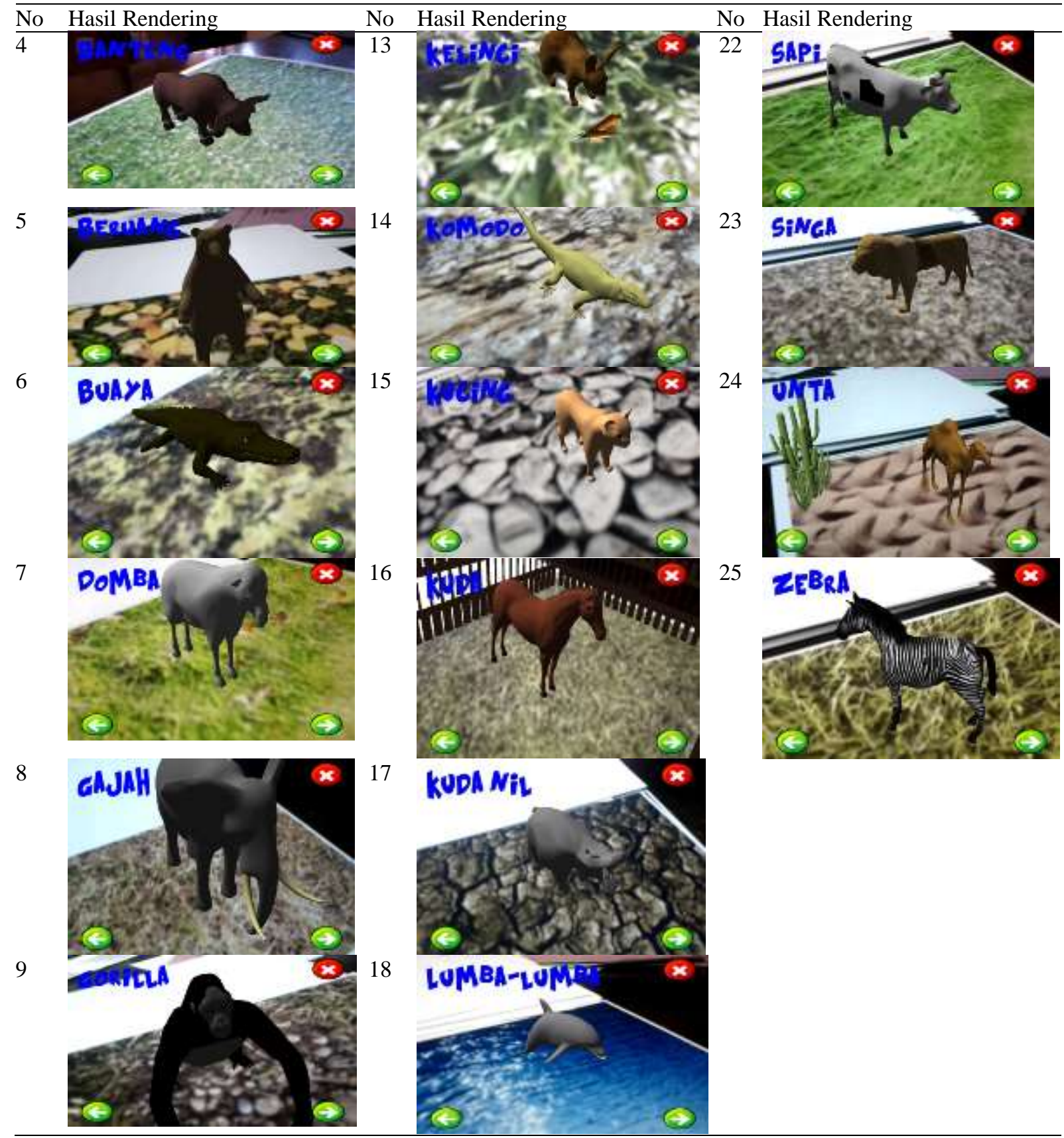

\subsubsection{Pengujian Performa}

Dalam proses ujicoba performa dari penelitian ini menggunakan beberapa parameter, yaitu ujicoba berdasarkan merk dan tipe smartphone, dan ujicoba pengguna serta analisis penggunaan smartphone.

\subsubsection{Berdasarkan Merk, Tipe dan Resolusi}

Pada proses ujicoba berdasarkan merk dan tipe smartphone, aplikasi ARnimal telah diujicobakan pada beberapa merk dan tipe smartphone, antara lain:

Tabel 2. Merk dan Tipe Smartphone

\begin{tabular}{llll}
\hline Perangkat & Prosessor & Resolusi & Status \\
\hline Nexus S & $1 \mathrm{GHz}$ & $480 \times 800$ & Valid \\
HTC Evo 3D & $1.2 \mathrm{GHz}$ & $540 \times 940$ & Valid \\
HTC Desire & $1 \mathrm{GHz}$ & $480 \times 800$ & Valid \\
Sony Ericsson Live & $1 \mathrm{GHz}$ & $320 \times 480$ & Valid \\
Walkman & & & \\
Galaxy W & $1.4 \mathrm{GHz}$ & $480 \times 800$ & Valid \\
Galaxy S & $1 \mathrm{GHz}$ & $480 \times 800$ & Valid \\
\hline
\end{tabular}


JURNAL MEDIA INFORMATIKA BUDIDARMA

Volume 4, Nomor 1, Januari 2020, Page 32-41

ISSN 2614-5278 (media cetak), ISSN 2548-8368 (media online)

Available Online at https://ejurnal.stmik-budidarma.ac.id/index.php/mib

DOI $10.30865 /$ mib.v4i1.1797

\subsubsection{Pengujian Blackbox}

Hasil dari pengujian blackbox ditunjukkan pada tabel berikut.

Tabel 3. Hasil Pengujian Black Box Testing

\begin{tabular}{|c|c|c|c|}
\hline No. & Kasus Uji & Kondisi & Hasil \\
\hline 1. & Tampilan Menu & User dapat melihat dan menggunakan tampilan menu utama aplikasi & Valid \\
\hline 2. & Alur Menu & User dapat menggunakan menu sesuai struktur dan fungsinya & Valid \\
\hline 3. & Deteksi Marker & $\begin{array}{l}\text { User dapat menggunakan marker untuk menampilkan obyek 3D maya } \\
\text { (Augmented Reality) }\end{array}$ & Valid \\
\hline 4 & $\begin{array}{l}\text { Rendering Obyek 3D } \\
\text { Hewan }\end{array}$ & $\begin{array}{l}\text { User dapat menjalankan kondisi augmented reality dengan melihat } \\
\text { hasil rendering obyek maya 3D hewan pada lingkungan nyata }\end{array}$ & Valid \\
\hline 5 & $\begin{array}{l}\text { Rendering Obyek 3D } \\
\text { Lingkungan/Pendukung }\end{array}$ & $\begin{array}{l}\text { User dapat menjalankan kondisi augmented reality dengan melihat } \\
\text { hasil rendering obyek maya 3D pendukung (seperti: pohon dll) pada } \\
\text { lingkungan nyata }\end{array}$ & Valid \\
\hline 6. & Animasi Obyek 3D & $\begin{array}{l}\text { User dapat melihat animasi obyek maya 3D seperti: hewan berjalan } \\
\text { dan sebagainya }\end{array}$ & Valid \\
\hline 7 & Informasi Hewan & User dapat melihat informasi nama hewan 3D maya & Valid \\
\hline 8 & ARbook & $\begin{array}{l}\text { User dapat memanfaatkan ARbook sebagai kumpulan marker yang } \\
\text { digunakan untuk menampilkan obyek maya 3D pada kondisi } \\
\text { augmented reality }\end{array}$ & Valid \\
\hline
\end{tabular}

\subsubsection{Ujicoba Pengguna}

Ujicoba pengguna dilakukan dengan memberikan kuesioner kepada 20 responden yang telah mencoba aplikasi ini dengan syarat pengguna tersebut tidak mengetahui atau tidak pernah mencoba sama sekali aplikasi berbasis augmented reality. Pada aspek penggunaan aplikasi, $50 \%$ responden merasa cukup mudah, $30 \%$ responden merasa kesulitan, 20\% responden merasa mudah dalam penggunaan aplikasi. Pada aspek tampilan, 50\% responden berpendapat cuku menarik, $45 \%$ responden berpendapat menarik dan hanya $5 \%$ responden yang menyatakan tidak menarik. Pada aspek edukasi, $60 \%$ responden menyatakan bahwa aplikasi ini membantu edukasi, $30 \%$ responden menyatakan bahwa aplikasi cukup membantu saja, dan hanya $10 \%$ responden yang berpendapat bahwa aplikasi ini tidak membantu. Pada aspek kemiripan obyek maya 3 dimensi dari hewan, $70 \%$ responden menyatakan mirip, $30 \%$ responden menyatakan cukup mirip, dan tidak ada responden yang menyatakan tidak mirip.

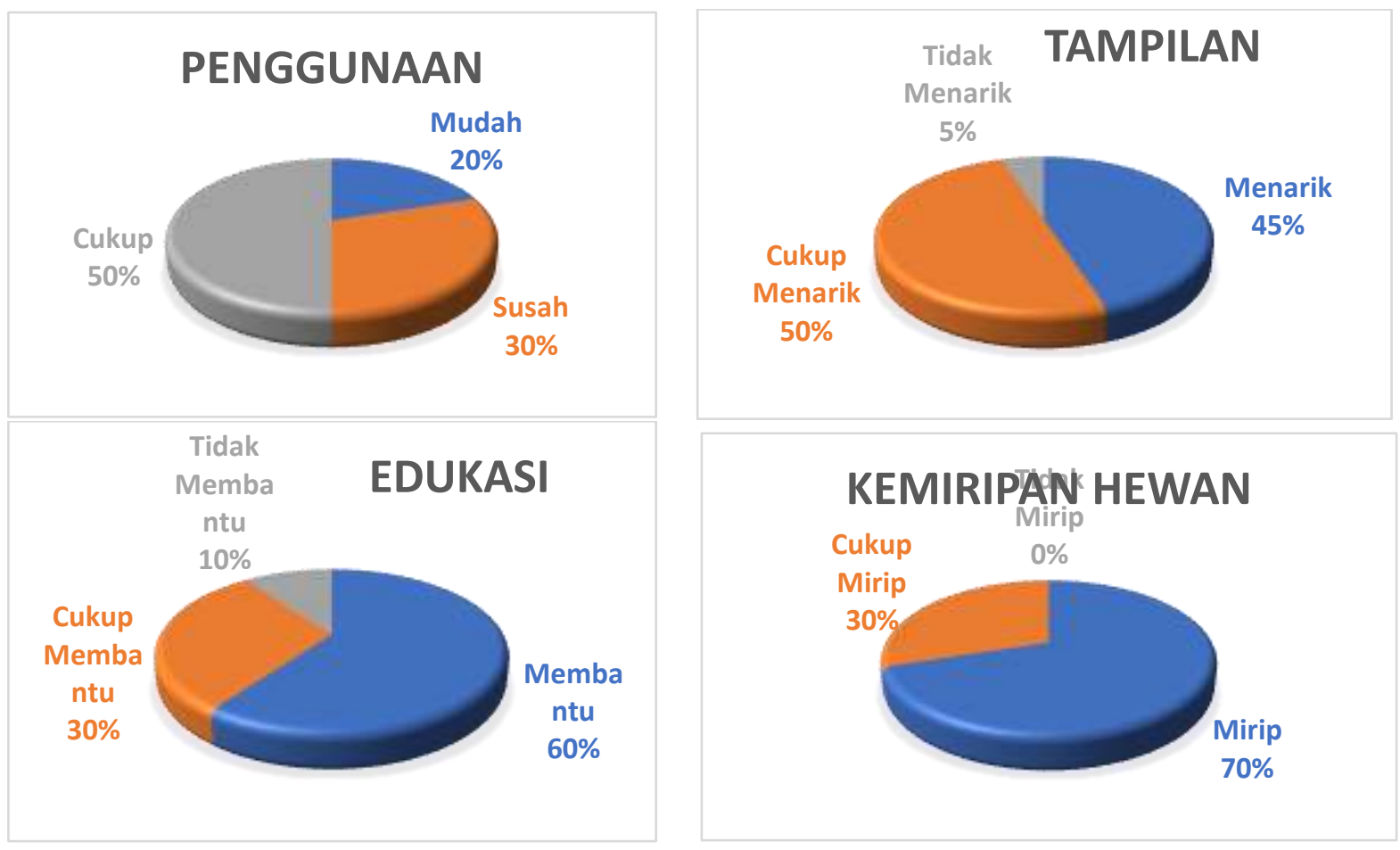

Gambar 11. Hasil Analisis Pengguna

Berdasarkan pengalaman dan percobaan dari ARnimal, aplikasi ini sudah berjalan dengan baik. Sejauh ini aplikasi berjalan lancar dan semua objek 3D hewan dapat ditampilkan pada layar smartphone. ARnimal bisa dibilang cukup berat karena banyaknya objek 3D yang dirender secara waktu nyata. Kemudian ARnimal juga membutuhkan smartphone dengan spesifikasi yang tinggi agar proses Augmented Reality dapat berjalan 
JURNAL MEDIA INFORMATIKA BUDIDARMA

Volume 4, Nomor 1, Januari 2020, Page 32-41

ISSN 2614-5278 (media cetak), ISSN 2548-8368 (media online)

Available Online at https://ejurnal.stmik-budidarma.ac.id/index.php/mib

DOI $10.30865 /$ mib.v4i1.1797

maksimal. Hal lain yang perlu diperhatikan dalam penggunaan aplikasi berbasis AR adalah faktor pencahayaan. Faktor ini mempengaruhi kestabilan pendeteksian marker. Jika intensitas cahaya terlalu besar atau lemah maka pendeteksian marker akan gagal atau obyek maya yang ditampilkan tidak stabil

\section{KESIMPULAN}

ARnimal merupakan media pembelajaran pengenalan hewan untuk anak yang menggunakan teknologi Augmented Reality (AR) berbasis Mobile Android. ARnimal terdiri atas buku bergambar yang berisi marker yang disebut ARbook dan aplikasi pada smartphone android untuk memproses Augmented Reality. Aplikasi ini membantu anak-anak untuk mengenal hewan-hewan di sekelilingnya. Pengguna dapat melihat dan belajar informasi tentang hewan-hewan pada ARbook, serta pengguna juga dapat melihat gambar 3 Dimensi hewan melalui smartphone yang menerjemahkan marker pada ARbook. Obyek maya hewan tersebut membantu pengguna untuk berimajinasi dan memahami jenis-jenis hewan yang ditampilkan. ARnimal telah diperkenalkan secara terbatas kepada sejumlah responden, hasilnya pengguna tidak mengalami kesulitan dengan interaksi yang ada pada ARnimal. ARnimal ini juga telah diuji cobakan kepada berbagai merek dan tipe smartphone android, hasilnya aplikasi tersebut berjalan tanpa ada gangguan. Pengujian blackbox menunjukkan bahwa semua fungsi berupa: tampilan menu, alur menu, deteksi marker, rendering obyek 3d hewan, rendering obyek 3d lingkungan/pendukung, animasi obyek 3D, dan informasi hewan berjalan dengan baik.ARbook juga berjalan dengan baik. Hal yang perlu diperhatikan dalam pengembangan aplikasi berbasis AR adalah faktor pencahayaan. Faktor ini mempengaruhi kestabilan pendeteksian marker. Jika intensitas cahaya terlalu besar atau lemah maka pendeteksian marker akan gagal atau obyek maya yang ditampilkan tidak stabil.

\section{REFERENCES}

[1] Mulyasa. (2006). Menjadi Guru Profesional Menciptakan Pembelajaran Kreatif dan Menyenangkan. Bandung: Penerbit PT Remaja Rosdakarya.

[2] Undang-Undang No. 20 Tahun 2003 tentang Sistem Pendidikan Nasional. Jakarta

[3] Dahar, Ratna Willis. 2006. Teori-teori Belajar dan Pembelajaran. Erlangga, Jakarta;

[4] Mu'in, Fatchul. (2012). Pendidikan Karakter; Konstruksi Teoritik \& Praktik. Jogjakarta: Ar RuzzMedia, p. 21;

[5] Masitoh, dkk. (2009). Strategi Pembelajaran TK. Surakarta: Universitas Terbuka.

[6] Narwati, Sri. 2011. Creative Learning: Kiat Menjadai Guru Kreatif dan Favorit. Yogyakarta: Familia.

[7] Chatib, Munif. 2012. Sekolahnya Manusia. Bandung: Kaifa Learning.

[8] Mubarikah, Husnul Rizka.2009.Perancangan Dan Implementasi Interaksi Untuk Media Pembelajaran Manasik Berbasis Teknologi Augmented Reality.Bandung: Institut Teknologi Bandung

[9] Sasmito, Anggar. 2011. Media Pembelajaran Sistem Tata Surya Berbasis Augmented Reality.Jakarta:Universitas Gunadarma.

[10] Riccitiello, John. Interview with Dean Takahashi. John Riccitiello sets out to identify the engine of growth for Unity Technologies (interview). October 23, 2014. Assessed on January 18, 2015.

[11] "Unity - Multiplatform". Unity. Retrieved 2018-12-05.

[12] "Subscription! Why? - Unity Blog". Unity Technologies Blog. Retrieved 2018-12-05.

[13] Technologies, Unity. "Unity - Manual: Unity User Manual (2018.2)". docs.unity3d.com. Retrieved 2018-12-05.

[14] "Unity Learn Tutorials". Unity. Retrieved 2018-12-05.

[15] Ronald T dan Azuma.1997. A Survey of Augmented Reality. Hughes Research Laboratories: Malibu

[16] Milgram, Paul; H. Takemura; A. Utsumi; F. Kishino (1994). "Augmented Reality: A class of displays on the realityvirtuality continuum" (pdf). Proceedings of Telemanipulator and Telepresence Technologies.

[17] https://www.ptc.com/en/products/augmented-reality

[18] https://en.wikipedia.org/wiki/Vuforia_Augmented_Reality_SDK 